\title{
Leucocytosis in Febrile Seizure
}

\author{
Ojha $A R^{1}$, Aryal UR ${ }^{2}$
}

${ }^{1}$ Dr. Anil Raj Ojha, MBBS. MD, Lecturer Department of Paediatrics, ${ }^{2}$ Umesh Raj Aryal, MSc (statistics), Lecturer in Community Medicine. Both from the Kathmandu Medical College Teaching Hospital, Sinamangal, Kathmandu.

Address for Correspondence: Dr. AR Ojha, E-mail: anilrojha@yahoo.com

\begin{abstract}
Introduction: Febrile seizure (FS) is a common condition affecting $2-5 \%$ of children. Peripheral blood leucocyte count with its differential is an initial test looking for the cause of fever and high count is usually accounted for the seizure activity. Objectives: To find the incidence of febrile seizure and to evaluate the relationship between fever duration before seizure, seizure duration and the total leucocyte as well as neutrophil response. Methodology: It is a cross sectional study done at Kathmandu Medical College and Teaching Hospital, Kathmandu, Nepal, for one year. After an informed consent, children from 6 months to 6 years with FS were admitted. Those with afebrile seizures and who refused to give consent were excluded. A detail history and examination was done on admission. All were investigated for the source of fever including total and differential count. Results: Out of a total 1742 children admitted, 115 (6.6\%) children had febrile seizure. Simple febrile seizure was observed in 93(81\%) and 22(19\%) was complex febrile seizure. $42 \%$ of them had leucocytosis. The duration of fever before the onset of seizure is found to be negatively correlated with total leucocyte count $(r=-0.418, p<0.001)$ and neutrophils count alone $(r$ $=-0.375, p<0.001)$. The duration of seizure is not correlated to both the total leucocyte count $(r=-0.162$, $p=0.85)$ and the neutrophil $(r=-0.109, p=0.247)$. Conclusion: The incidence of febrile seizure is $6.6 \%$. Leucocytosis and neutrophilia in children is negatively correlated with the duration fever before the onset of seizure, associated with underlying infection if any and is not related to seizure event and its duration. Thus any child with febrile seizure with high leucocyte count should be evaluated for infection.
\end{abstract}

Key words: Fever, Leucocytosis, Neutrophilia, Seizure

\section{Introduction}

Febrile seizure (FS) is defined as an event in neurologically healthy infants and children between 6 months and 6 years of age, associated with fever of $>38^{\circ} \mathrm{C}$ rectal temperature but without the evidence of intracranial infection as a defined cause and with no history of prior afebrile seizures ${ }^{1}$.

It is a common problem in children, affecting $2-5 \%$ of them ${ }^{2}$. Recognizing the source of fever is important in its management. It is the peripheral blood count with its differential, which is commonly done at the beginning to look for the cause of fever ${ }^{3}$. Many times we come across high total blood leucocyte count in these children. There are studies which have shown the direct effect of seizure on peripheral cell count ${ }^{4,5}$. Studies have also shown that the stress from fever or seizure results in leucocytosis with neutrophilic predominance following release of epinephrine $^{6}$. Most of the time the high leucocyte count in children with febrile seizure is supposed to be related with seizure activity and ignored. Thus this study aims to find out the relationship between fever, seizure and leucocytosis.

\section{Objectives}

1. To study relationship between leucocytosis and fever duration before onset of seizure in children with febrile seizure.

2. To study the relationship between leucocytosis and seizure duration in children with febrile seizure.

\section{Material and Methods}

This was a cross sectional study done at Kathmandu Medical College and Teaching Hospital, Sinamangal, Kathmandu, Nepal. The study period was from 1st 
Asar 2065 (15 June 2008) to $31^{\text {st Jestha }} 2066$ (14 June 2009). After an informed consent, all the children from 6 months to 6 years with febrile seizures were included in the study. Children below 6 months and above 6 years, those with afebrile seizures and who refused to give consent were excluded from the study.

A detailed history was obtained from the parents including description of the seizure, symptoms pertaining all the systems, presence or absence of focal features, duration of the febrile seizure and whether repeated episodes within the same febrile illness occurred and the duration of fever prior to the seizure.

On arrival, temperature was measured. Total leucocyte count, differential count, Hemoglobin, was done in each child. Other investigations were done when necessary as decided by the treating physician. Total count $>15000$ per cu $\mathrm{mm}$ was regarded as leucocytosis ${ }^{4}$.

Simple febrile seizures were pre-defined as generalized seizures, lasting less than $15 \mathrm{~min}$, not recurring within 24 hours, and with no postictal neurological abnormalities. Similarly, complex febrile seizures were focal, prolonged or recurrent within 24 hours or associated with post-ictal neurological abnormalities including Todd paresis ${ }^{7}$.
The collected data were entered in excel and analyzed using SPSS 11.5. Data were analyzed by using Descriptive statistics (Median, range) and Spearman correlation. $\mathrm{P}<0.05$ was taken as statistical significant.

\section{Results}

During the study period, 1742 patients got admitted in the Paediatric ward. 115(6.6\%) of them were admitted for febrile seizure. There were $71(62 \%)$ boys and 44 $(38 \%)$ girls. The mean age (SD) of the children in the study population was $26.5( \pm 15.17)$ months.

Simple febrile seizure was observed in 93(81\%) and the rest 22(19\%) was complex febrile seizure. Among those who had complex febrile seizure, $7(6 \%)$ had focal seizure, $7(6 \%)$ had seizure duration $>15$ minutes and $8(7 \%)$ had more than 1 seizure within 24 hour of onset of fever. Characteristics of children enrolled in the study are shown in table 1 . Out of 115 cases $48(42 \%)$ had leucocyte count of $>15000$ per cu $\mathrm{mm}$. The duration of fever before the onset of seizure was found to be negatively correlated with total leucocyte count $(r=$ $-0.418, p<0.001$, Spearman correlation analysis). There is also a negative correlation for neutrophils $(r=-0.375$, $p<0.001$, Spearman's correlation analysis). The duration of seizure has a weak negative correlation to both the total leucocyte count $(r=-0.162, p=0.85)$ and the neutrophil $(r=-0.109, p=0.247)$ though they were not statistically significant.

Table 1: Descriptive characteristics of children with febrile seizure.

\begin{tabular}{|l|c|c|c|}
\hline & Number & Median & Range \\
\hline Fever to seizure duration (hours) & \multirow{3}{*}{115} & 12 & $1-72$ \\
\cline { 1 - 1 } Duration of seizure (minutes) & & 4 & $1-30$ \\
\hline Total leucocyte count (microliter) & & 13100 & $4000-35400$ \\
\hline Neutrophil (\%) & & 72 & $45-93$ \\
\hline
\end{tabular}

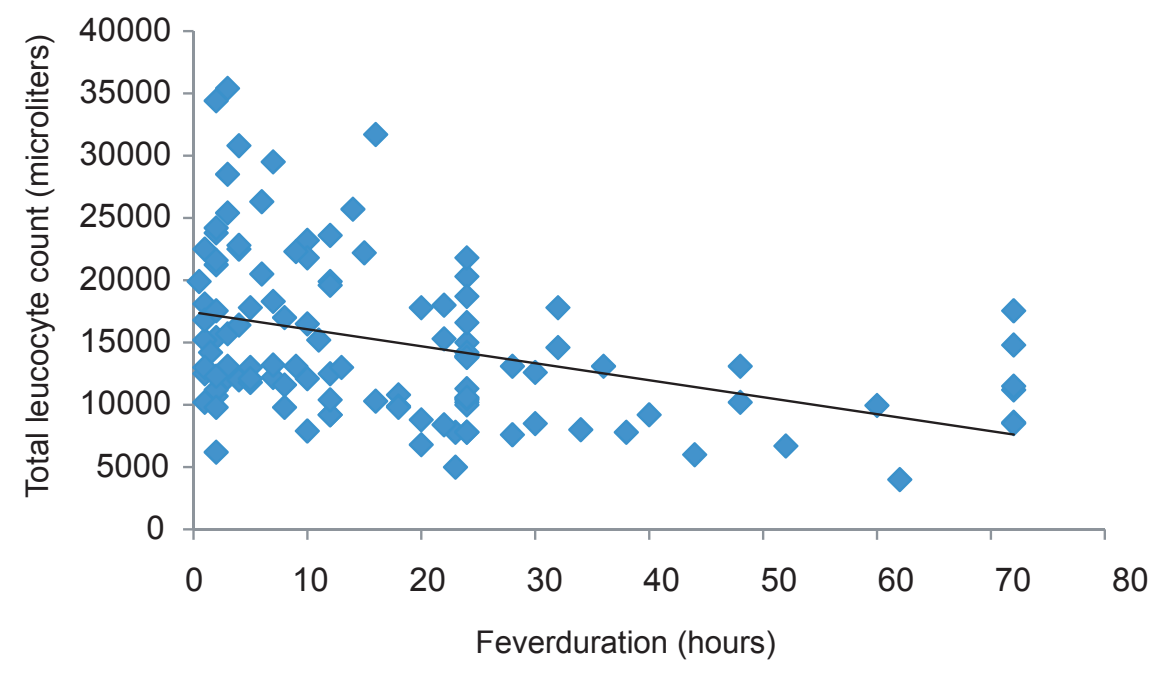

Fig 1: Spearman rank correlation between total leucocyte count and fever duration prior to seizure. 


\section{Discussion}

The incidence of febrile seizure in the study population was $6.6 \%$, which is higher to other study. In our study, the mean age of the children with FS was 26.5 months which is comparable to other studies ${ }^{8,9}$. It was the simple febrile seizure that accounted the majority of case $(81 \%)$. Other studies ${ }^{8,10}$ also had supported this finding.

Male sex accounted for higher percentage (62\%) among the study children. Trainor $\mathrm{JL}$ et $\mathrm{al}^{9}{ }^{9}$ in their study had shown that $64 \%$ of study population was male. Other studies ${ }^{11,12,13}$ also had shown that it is the male children who were predominantly affected.

Fever and neutrophilia is induced by interleukin- $1^{14}$. Also interleukin-1 causes a high leucocyte count ${ }^{15}$. Usually in cases of infection there is elaboration of endogenous pyrogen like interleukin. Moreover interleukin-1 stimulates the secretion of cortisol ${ }^{14}$. Cortisol as a result induces leukocytosis and neutrophilia ${ }^{16}$. This study has shown that there is a negative correlation between total leucocyte count, neutrophil count alone and the duration of fever before the onset of seizure. A study by Dinarello CA showed that in patients with normal marrow store, acute increase in total leucocyte count after administration of interleukin-1 is predominantly due to absolute neutrophilia ${ }^{14}$. Ulich et al reported that with fever and seizure, epinephrine causes neutrophilia solely due to demarginalization of neutrophils secondary to stress and infection, whereas in interleukin-1-treated rats is accompanied by depletion of marrow neutrophils ${ }^{6}$. This could explain the negative correlation between the duration of fever before the febrile seizure and total blood leukocyte and neutrophil counts in our study. Thus, this does not rule out the possibility of infection as cause of leucocytosis and neutrophilia. In his studies, Lahat et al found that there was no significant difference in the levels of interleukin-1 in blood and cerebrospinal fluid of children with febrile seizures than those of children with febrile illnesses without seizure ${ }^{17}$. These findings suggests leucocytosis is related to fever rather than the seizure event. This study showed that there is no significant correlation between leucocytosis and seizure duration. Thus, in this study, the reason for leucocytosis was due to febrile episode rather than seizure event or duration. This is supported by other studies which showed no correlation between leucocytosis and seizure duration ${ }^{4,18}$.

\section{Conclusion}

Febrile seizure is a common problem in children. Leucocytosis and neutrophilia in children with febrile seizure is negatively correlated with the duration of fever before the onset of seizure and the underlying infection if any. It is not in any means related to seizure event and its duration. Thus, any child with febrile seizure with a high leucocyte count should be evaluated for infection and the total blood count with its differential is an initial good tool in evaluating the cause of fever in all these children.

\section{Acknowledgement: None \\ Funding: None \\ Conflicting Interests: None \\ Permission from IRB: Yes}

\section{References}

1. AAP Consensus Development Panels. Febrile seizures: Long-term management of children with fever associated seizures. Pediatrics. 1980;66:1009-12.

2. Ostergaard JR. Febrile seizures: Acta Paediatr. 2009;98(5):771-3.

3. American Academy of Pediatrics: Practice parameter: The neurodiagnostic evaluation of the child with first simple febrile seizure. Pediatrics 1996;97:769-772.

4. Van Stuijvenberg M, Moll HA, Steyerberg EW, van Gijssel EN, Moons KG, Derksen-Lubsen G. The duration of febrile seizures and peripheral leucocytosis. J Pediatr 1998;133(4):557-8.

5. Senn HJ, Jungi WF: Neutrophil migration in health and disease. Semin Hematol 1975;12:27-45.

6. Ulich TR, del Castillo J, Ni RX, et al: Mechanism of tumor necrosis factor alpha-induced lymphopenia, neutropenia and biphasic neutrophilia: a study of lymphocyte recirculation and hematologic interactions of TNF alpha with endogenous mediators of leucocyte trafficking. J Leuko Biol 1989;45:155-67.

7. Pratibha D. Singhi, M. Srinivas. Febrile seizures. Indian Paediatrics 2001;38:733-40.

8. Millichap JJ, Gordon Millichap J. Method of investigation and management of infections causing febrile seizures. Paediatr Neurol 2008;39(6):381-6.

9. Trainor JL, Hampers LC, Krug SE, Listernick R. Children with first time simple febrile seizures are at low risk of serious bacterial illness. Acad Emerg Med 2001;8(8):781-7. 
10. Mustafic N, Tahirovic H, Trnovcevic J, Kapidzic A. Clinical characteristics at onset of first febrile convulsions. Acta Med Croatia 2008;62(5):511-5.

11. Bessisso MS, Elsaid MF, Almula NA, Kadomi NK, Zeidan SH, Azzam SB, et al. Recurrent risk after a first febrile convulsion. Saudi Med Journal $2001 ; 22(3): 254-8$.

12. Pavlidou E, Tzitiridou M, Kontopoulos E, Panteliadis CP. Which factors determine febrile seizure recurrence? A prospective study. Brain Dev 2008; 30:7-13.

13. Zhao F, Emoto SE, Lavine L, Nelson KB, Wang CC, $\mathrm{Li}$ SC, et al. Risk factors for febrile seizures in the People's Republic of China: a case control study. Epilepsia 1991;32(4):510-4.

14. Dinarello CA. Biologic basis for interleukin-1 in disease. Blood 1996;87:2095-147.
15. Foantana A, Kristensen F, Dubs R, et al: Production of prostaglandin $E$ and interleukin-1 like factor by cultural astrocytes and c6 glioma cells. J Immunol 1982;129:2413-9.

16. Tonnesen E, Christensen NJ, Brinklov MM: Natural killer cell activity during cortisol and adrenaline infusion in healthy volunteers. Eur J Clin Invest 1987;17:497-503.

17. Lahat E, Livne M, Barr J, Katz Y: Interleukin-1 in serum and cerebrospinal fluid of children with febrile seizures. Pediatr Neurol 1997;17:34-6.

18. Mohebbi MR, Holden KR, Mohammadi M. Peripheral leucocytosis in children with febrile seizures. J Child Neurol 2004;19(1):47-50.

\section{How to cite this article?}

Ojha AR, Aryal UR. Leucocytosis in Febrile Seizure. J Nepal Paediatr Soc 2011;31(3):188-191 